\title{
La función propedéutica del sofista y la emergencia del filósofo. División, dialéctica y paradigmas en el diálogo Sofista
}

\author{
Lucas Álvarez \\ CONICET/ Universidad de Buenos Aires
}

Resumen: El propósito de este trabajo es examinar la cuestión de los objetivos planteados por Platón en el diálogo Sofista. En primer lugar, procuramos echar luz sobre el objetivo general que se estaría trazando en el prólogo de la obra, allí donde el Extranjero de Elea comienza a demostrar su estatus filosófico. En segundo lugar, nos ocupamos de ubicar la caracterización del sofista en el marco de ese objetivo, interpretando el resultado de dicha caracterización como un $\pi \alpha \rho \alpha ́ \delta \varepsilon \imath \gamma \mu \alpha$ implícito que prepara la ejecución de la dialéctica y anticipa los rasgos de un objeto clave de esa ciencia.

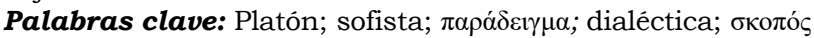

Abstract: “The Propedeutic Role of the Sophist and the Emergence of the Philosopher. Division, Dialectic and Paradigms in Plato's Sophist'. This paper will examine the issue of Plato's purposes in the Sophist. First, we will shed light on the main purpose Plato might be drawing in the prologue of the dialog, where the Eleatic Stranger begins to show his philosophical status. Then, we will locate the sophist's characterization within this main purpose, by reading the result of this characterization as an implicit $\pi \alpha 0 \alpha \delta \varepsilon \uparrow \gamma \mu \alpha$ which prepares the execution of the dialectic and anticipates the defining features of an object key to this science.

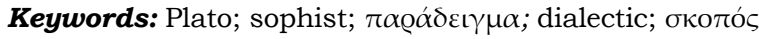




\section{Introducción}

La tenaz polémica anti-sofistica que Platón despliega a lo largo de su obra parece hallar en el diálogo Sofista su punto más álgido. Sin embargo, aquí buscaremos demostrar que el foco hacia el que convergen las líneas argumentales de dicho diálogo no es la caracterización del sofista, sino, muy por el contrario, la explicitación del perfil del filósofo, operación que se alcanza a través de la ejecución de la ciencia dialéctica. En este sentido, intentaremos probar que aquella caracterización se encuentra al servicio de esta explicitación por razones que van mucho más allá de la posibilidad que tiene el sofista de oficiar de contracara del filósofo. Con esos fines, en la sección I, buscaremos echar luz sobre los objetivos generales de la obra que parecen formularse en el prólogo de la misma, allí donde Sócrates pone en cuestión la condición filosófica del Extranjero de Elea. Por otra parte, en la sección II, procuraremos ubicar la caracterización del sofista en el plan general de la obra, lo que nos comprometerá con ciertas dimensiones metodológicas y ontológicas del diálogo. En efecto, por medio de esa caracterización, los interlocutores sientan las bases de la dialéctica y anticipan los rasgos del no-ser, objeto clave del ámbito eidético que se examina en el corazón del diálogo.

\section{$I$}

La cuestión de los objetivos que Platón se plantea en cada uno de sus diálogos ha adquirido absoluta relevancia desde la época de los comentaristas neoplatónicos ${ }^{1}$. De hecho, buena parte de ellos suele comenzar sus comentarios examinando, justamente, el "objetivo" (бколós) de cada obra. Ahora bien, a diferencia de otros diálogos, el Sofista no parece contar ni con un objetivo claro ni con una evidente unidad temática ${ }^{2}$. En este sentido, en el capítulo

\footnotetext{
1 Al respecto, véase Prolegómenos a la filosofia de Platón (15-6) y sobre este pasaje, consúltese: Motta, A., "The Visible Cosmos of Dialogues: Some Historical and Philosophical Remarks about Plato in the Late Antique Schools", en: Archai, v. XII (2014), pp. 11-18. Seguimos la traducción de: Anónimo, Prolegomena to Platonic Philosophy, Westerink, L. (trad.), Amsterdam: North-Holland Publishing Co., 1962.

2 Cf. Platón, Diálogos V: Parménides, Teeteto, Sofista, Politico, Cordero, N. (trad.), Madrid: Gredos, 1988, pp. 322-323.

ARETÉ Revista de Filosofía, vol. XXVIII, N² 2, 2016 / ISSN 1016-913X
} 
IX de Prolegómenos a la filosofía de Platón, el autor anónimo presenta cinco candidatos para ocupar el бкотóৎ del Sofista, a saber: la figura homónima, el método de la división, lo que no es, lo que es, e incluso, retomando una singular interpretación de Jámblico, la figura de un demiurgo sublunar³. Inclinado por la primera de esas posibilidades, Proclo supone que dicho бколó definición del sofista, pues a pesar de la extensión de los pasajes dedicados al estatus del no-ser o del énfasis puesto en la presentación y uso del método de la división, lo cierto es que ambas cuestiones son discutidas solo en bien del бколós principal ${ }^{4}$. Por otro lado, en relación con la manifestación de los бколоí, el mismo Proclo sostiene que, al estudiar un diálogo platónico, es necesario leer con detenimiento el prólogo del mismo, ya que es en las líneas inaugurales donde suele prefigurarse el tema y los objetivos principales 5 . Platón parece haber prestado especial atención a los prólogos (Diógenes Laercio nos transmite la anécdota de las numerosas reescrituras que sufrió el prólogo de República) ${ }^{6}$ y aunque esa preocupación pudo haber sido meramente estilística, el contenido de las palabras que abren los diálogos nunca debe soslayarse. Detrás de una aparente conversación banal, Platón suele esconder detalles clave del diálogo. Por lo tanto, a continuación -y siguiendo la postura de Proclo- nos ocuparemos de leer el prólogo de Sofista con el objeto de revisar la posible explicitación de su бкотós.

En las líneas iniciales, Teodoro anuncia a Sócrates que lo acompaña un extranjero originario de Elea y le aclara que "aunque diferente de los compañeros de Parménides y de Zenón; este hombre, no obstante, es todo un filósofo" (216a3-4)7. Sócrates duda y le pregunta si acaso “¿no traerás un dios, según

\footnotetext{
3 Sobre la lectura de Jámblico, cf. Tarrant, H., Plato's First Interpreters, Nueva York: Cornell University Press, 2000, pp. 93-94.

4 Comentario sobre la República I, 8 23-28 y Comentario al Parménides I, 637 9-12. Seguimos las siguientes traducciones: Proclo: Commento alla Repubblica di Platone, Abbate, M. (trad.), Milán: Bompiani, 2004 y Morrow, G.R. y J.M., Dillon, Proclus' Commentary on Plato's Parmenides, Princeton: PUP, 1987.

5 Parménides, I, 659. Vale destacar que, antes de presentar su opinión, Proclo ofrece un resumen histórico de las posiciones tomadas en relación con el valor de los prólogos en los diálogos platónicos. Sostiene que los primeros comentadores no consideraron significativo estudiar las partes introductorias, que otros suponian que en esas partes se brindaban lecciones morales aunque sin relación con los temas principales y, finalmente, que algunos comenzaron a juzgar que los prólogos estaban vinculados con el бколó

6 Diógenes Laercio III, 37. Sobre este testimonio, véase Riginos, A.-S., Platonica: the Anecdotes concerning the Life and Writings of Plato, Leiden: Brill, 1976, pp. 185-186.

7 La traducción aquí y en citas siguientes le corresponde a la edición de Néstor Cordero. Los casos en los que se opta por una traducción alternativa se encuentran debidamente señalados. Sobre la elección del término êtẹov, consúltese Cordero, N., "El Extranjero de Elea, 'compañero'
} 
decía Homero? Pues este sostenía que a los hombres respetuosos de la justicia los acompañan los dioses..." (216a5-b1). Frente a esta intervención, Teodoro sostiene que esa no es la índole del extranjero y que, en su opinión (бокعiv, 216b9), "no es en absoluto un dios, si bien es un ser divino ( $\theta \varepsilon \tilde{\varepsilon}(\varsigma)$, pues este es el calificativo que yo otorgo a todos los filósofos" (216b8-c1). Inmediatamente, Sócrates afirma que la clase de los filósofos no es más fácil de discernir que la divina, pues si bien "toda esta clase de hombres tiene el aspecto ( $\varphi \alpha \nu \tau \alpha \zeta o ́ \mu \varepsilon v o \iota)$ de 'merodear por las ciudades' en medio de la ignorancia (ă $\gamma v o t \alpha)$ de la gente,

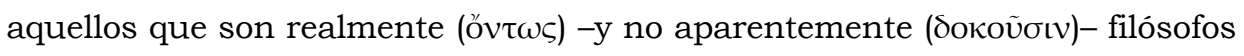
observan desde lo alto la vida de acá abajo y, así, para unos, no valen nada, mientras que para otros son dignos de todo. Algunas veces tienen el aspecto

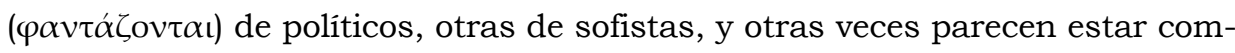
pletamente locos" (216c4-d2).

En las líneas citadas, Teodoro comienza presentando a su compañero por medio de tres características: su tierra de origen, sus diferencias con los compatriotas Parménides y Zenón, y su condición filosófica ${ }^{8}$. Sin embargo, esa presentación es cuestionada por un Sócrates que sugiere -de manera irónica y apelando a Homero- que quizás ese extranjero sea un dios ${ }^{9}$. La apelación a los poemas homéricos es deliberada porque, lineas después, el mismo Sócrates retoma pasajes específicos de Odisea ${ }^{10}$. En el contexto original de esos pasajes, uno de los pretendientes de Penélope exhorta a Antínoo a comportarse de manera justa con el mendigo que acaba de golpear (mendigo que, en realidad, no es otro que Odiseo disfrazado), pues le advierte que, a menudo, los dioses recorren las ciudades bajo la forma de extranjeros y con otros aspectos para

de los parmenídeos...desde 1561" en: Cornelli, G. (ed.), Plato's Styles and Characters, São Paulo: Annablume Clássica, 2012, pp. 124-138.

8 Cf. Blondell, R., The Play of Character in Plato's Dialogues, Cambridge: CUP, 2002, pp. 314-320, sostiene que la ausencia de cualquier otro tipo de caracterización del extranjero (quien carece de las características que definen a cualquier personaje de los diálogos platónicos, incluso a aquellos no-atenienses de los que usualmente se mencionan su estatus social, su identidad cívica y su métier) sugiere un interés en remarcar lo genérico a costa de lo individual y, teniendo en cuenta que ese interlocutor termina reemplazando a Sócrates como portavoz de Platón, un camino hacia la ausencia de individuación en la presentación del filósofo.

9 Dicha ironía es remarcada por Bluck, R., Plato's Sophist. A commentary, Bristol: The University Press, 1975, p. 30. Sobre el uso de la ironia socrática, véase Vlastos, G., Socrates. Ironist and Moral Philosopher, Cambridge: CUP, 1991, pp. 21-44, para quien ese recurso resulta, en boca de Sócrates, benigno y desprovisto de todo tipo de engaño. A diferencia de Nehamas, A., The Art of Living: Socratic Reflections from Plato to Foucault, Berkeley: University of California Press, 1998, p. 62, Vlastos sostiene que Sócrates expone su verdad diciendo lo contrario de lo que quiere decir, sin apelar a ningún otro tipo de engaño u ocultamiento.

10 Téngase en cuenta que los mismos pasajes aludidos en esas lineas de Sofista son citados en República II, 381d. 
vigilar la soberbia de los hombres o su rectitud (Odisea XVII, 485-7). Por medio de la cita homérica, Sócrates destaca, en primer lugar, esa vigilancia divina de los asuntos humanos, pero termina haciendo fuerte hincapié en la cuestión de las apariencias que no concuerdan con lo real. De este modo, equipara a los filósofos con los dioses admitiendo que ambos son dificiles de discernir debido a sus variadas apariencias. El planteo parece sugerir que poco puede decirse del sujeto que acompaña a Teodoro sobre la base de su mera apariencia, ya que ese extranjero considerado "todo un filósofo" puede en realidad no serlo. Ahora bien, si nos detenemos en la equiparación socrática veremos que, nuevamente, funciona en clave irónica, pues si, por un lado, esconde diferencias insalvables entre dioses y filósofos, por el otro, anticipa -en realidad- el contraste entre filósofos y sofistas.

Más allá de la vinculación que en otros diálogos suele plantear Sócrates entre dioses y filósofos ${ }^{11}$, aquí la analogía resulta irónica en la medida en que el término de comparación no es el tipo de dios que él venera (un dios que, debido a su perfección y simpleza, no abandona ni modifica su aspecto), sino el tipo de dios homérico que, como hechicero y por medio de variados artificios, aparece de numerosas formas. Por su parte, el filósofo -tal como es presentado en el diálogo Teeteto- es aquel que se despreocupa de la buena reputación

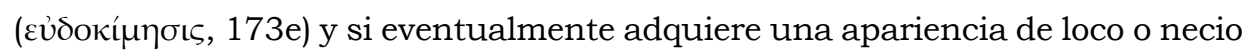
(174c) ella se debe más a la ignorancia de los otros que a su propia voluntad ${ }^{12}$. En este sentido, las figuras de los dioses polimórficos y del filósofo se alejan inevitablemente. La cuestión de la voluntad en la proyección de apariencias es fundamental porque en las líneas del Sofista que hemos citado, Sócrates relativiza las diversas apariencias que los filósofos adquieren en la ciudad incorporando la noción de áyvoı $\alpha$ (216c5). Los posibles aspectos de los filósofos (loco, sofista o político) deben comprenderse como efectos de la "ignorancia" reinante entre la mayoría que puebla la тódıৎ y, por ende, involuntarios ${ }^{13}$, mientras que

\footnotetext{
${ }^{11}$ Sobre esa vinculación véase, por ejemplo, Fedro 249c-d, Filebo 16c-e y Timeo 89d-90d.

12 Recordemos que Sócrates apela a una anécdota de Tales en la que el pensador de Mileto, absorto en sus investigaciones astronómicas, cae en un pozo, provocando las burlas de una sirvienta tracia (174a). Así, dice Sócrates, ocurre con todos los filósofos, pues "a una persona de esta índole el que está cerca y el vecino le pasan inadvertidos” (174a-b). Desde la óptica socrática, los filósofos se desinteresan de su propia reputación y, por ello, la apariencia de que Tales podría adquirir a los ojos de la sirvienta tracia nace de la ignorancia de esta y no de la voluntad de aquel.

${ }^{13}$ En este punto la traducción de Diès, A., Platon, Le sophiste. Oeuvres complètes, t. VIII, 3ra parte, París: Les Belles Lettres, 1923, es clara: “...cette sorte d'humains prend d'apparences différentes dans le jugement ignorant de la foule...” (216c). Sobre los diversos aspectos de los filósofos como consecuencia de la ignorancia de la multitud, véase Dixsaut, M., "Images du philosophe", en: Kleos, v. IV, 4 (2000), pp. 191-248, p. 216.
} 
los dioses homéricos se caracterizan por gestionar voluntariamente sus apariencias con el objeto de engañar a sus receptores. Y es por esta razón por la que la equiparación socrática, tal como afirmamos, anticipa una confusión entre filósofos y sofistas. Son estos últimos los que, como aquellos dioses homéricos, se distinguen por su gestión voluntaria y engañadora de apariencias y, por ello, si ante la ignorancia de la mayoria un filósofo puede pasar por sofista, a la inversa, un sofista podría pasar por filósofo. Ante los ojos de Sócrates, esa mayoría es incapaz de distinguir entre uno y otro.

Entonces, el problema central que parece plantearse en las lineas inaugurales del diálogo radica en la posibilidad de distinguir entre alguien que es

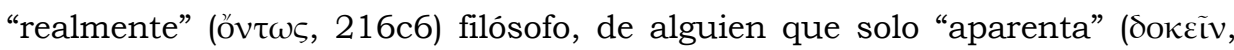
216c7) serlo. Y frente a esta problemática, Teodoro y Sócrates proceden de modos

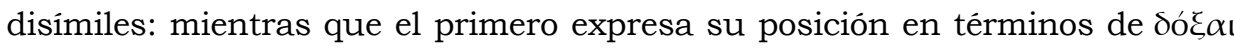
(216b9), Sócrates ensaya algunas conjeturas irónicas, evita expresar opiniones $\mathrm{y}$, finalmente, en un gesto trascendental del diálogo, decide dilucidar el estatus del Extranjero interrogándolo. En efecto, Sócrates le pregunta cómo conciben y cómo llaman los de su "región" (тóтos, 217a1) al sofista, al político y al filósofo e indica que, particularmente, desea saber si los conciben a todos ellos como uno, como dos o "...puesto que hay tres nombres, consideran que hay tres especies ( $\gamma \varepsilon \dot{v} \eta)$, a cada una de las cuales le corresponde un nombre (övo $\alpha \alpha)$ " $(216 e-217 a)^{14}$. Teodoro sugiere que el Extranjero no tendrá "inconvenientes" ( $\varphi$ Өóvos, 217a9) en explicar lo que se le pide y este, confirmando la ausencia de inconvenientes, sostiene que los de su "región" los conciben como tres especies,

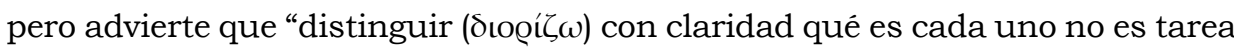
fácil ni pequeña" (217b). Por lo tanto, buscando zanjar la dificultad que se ha planteado (la distinción ente un filósofo real y un filósofo aparente), Sócrates

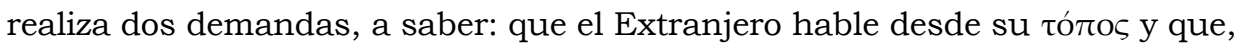
al hacerlo, opere distinguiendo especies.

Con respecto al término тó đos, algunos intérpretes han advertido que se encuentra cargado de ambigüedad porque puede o hacer referencia a la tierra

${ }^{14}$ Cf. Palumbo, L., Il non essere e l'apparenza: sul Sofista di Platone, Nápoles: Loffredo, 1994, p. 29 n.14, quien sugiere que, en esas lineas, la intención de Sócrates es superar la particularidad de un punto de vista basado en la subjetividad de la opinión para alcanzar una perspectiva que pueda captar "la objetividad de la verdad". Casertano, G., Il nome della cosa. Linguaggio e realtà negli ultimi dialoghi di Platone, Nápoles: Loffredo, 1996, pp. 92-93, afirma que, siendo conscientes de que lo que único que se tiene en común es un mero nombre, los interlocutores comienzan a buscar un $\lambda$ ó $\gamma$ os que le permita hacer manifiesto sobre el plano del ser aquello a lo que se refiere el nombre en cuestión. 
de origen de ese personaje o bien al lugar de los de su especie, i.e. al lugar de los filósofos (si respetamos la condición que le adscribe Teodoro al comienzo) ${ }^{15}$. No obstante, esa ambigüedad puede disiparse si tenemos en cuenta el contexto inmediato en el que dicho término se incorpora. En este sentido, es necesario, en primer lugar, destacar que lo que está en juego desde el comienzo de la discusión no es la tierra de pertenencia de ese personaje (es de Elea y nadie lo objeta), sino la condición filosófica que le asigna Teodoro. En segundo lugar, debe señalarse que justo antes de introducir el término tó hace referencia a un par de coordenadas espaciales para hablar precisamente de la tarea del filósofo. Por medio de dichas coordenadas -que vuelven a jugar con la analogía divina16 - ubica al filósofo en lo alto "mirando hacia abajo"

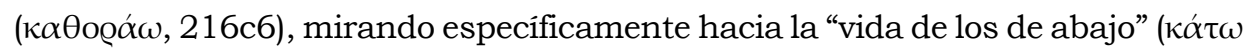
Bíov, 216c7). En tercer lugar, cabe advertir que el término al que Teodoro apela para negar "inconvenientes" de parte del Extranjero se vincula con el quehacer filosófico. "ФӨóvoৎ" comporta los sentidos de "envidia" o "celo"17, y en aquellas líneas es utilizado para indicar que el Extranjero ofrecerá a sus interlocutores todos sus saberes sin reservas en la medida en que no siente celos. Siguiendo a Brisson, podemos afirmar que el celoso de su saber retiene información porque está preocupado por la idea de compartir una ventaja y/o de convertir al otro en sabio y, por esta razón, el $\varphi \boxminus$ óvoৎ es absolutamente incompatible con el diálogo filosófico: aquel que sabe algo (incluso aquel que sabe que no sabe) debe poner sus conocimientos al servicio del otro para así descubrir juntos la verdad ${ }^{18}$.

Teniendo en cuenta esas tres cuestiones -la discusión sobre el estatus filosófico del Extranjero, las coordenadas espaciales sobre el lugar del filósofo y la negación de ese sentimiento que representa una traba para la actividad filosófica- resulta preciso inclinarse por la segunda alternativa que planteábamos a propósito del término tónos y pensar que él hace referencia al lugar de los filósofos. Por lo tanto, dejando de lado las conjeturas y evitando las opiniones, Sócrates invita al Extranjero a intervenir en el diálogo y a demostrar, como miembro representativo de la región de los filósofos, su discutido estatus.

\footnotetext{
15 Véase Benardete, S., The Being of the Beautiful. Plato's Theaetetus, Sophist and Statesman. Translated with Commentary, Chicago: Chicago University Press, 1984, pp. 72-73 y Scodel, H., Diaeresis and Myth in Plato's Statesman, Gotinga: Vandenhoeck und Ruprecht, 1987, p. 22, n.4.

${ }^{16}$ Cf. Rosen, S., Plato's Sophist. The Drama of Original and Image, New Haven: Yale University Press, 1983, p. 65.

${ }^{17}$ Cf. Liddell, H. y J. Scott, Greek English Lexicon, 9na edición, Oxford: Clarendon Press, 1996, s.v. ' $\varphi$ Өóvos'. En adelante, LSJ.

${ }^{18}$ Cf. Brisson, L., Lectures de Platon, París: Vrin, 2000, p. 223. Al respecto, véase Menón 71d.
} 
El бкотós del diálogo Sofista radicaría entonces en esa demostración por medio de la cual el Extranjero se desplaza desde el plano de las apariencias (en el que hasta ahora se estaba librando la discusión) hasta el plano dialógico. Ahora bien, en este último plano, ese personaje debe comenzar respondiendo el desafio que le ha planteado Sócrates -que consiste, como vimos, en la distinción de

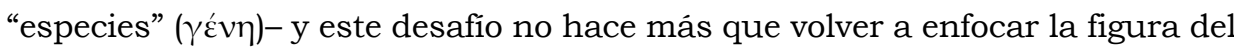
filósofo. En efecto, más allá de lo que debe distinguirse (en este caso, el sofista, el político y el filósofo), lo cierto es que los términos en los que se expresa el desafio socrático anticipan los quehaceres filosóficos que se revelarán en el corazón mismo del diálogo.

Resumiendo el argumento posterior al prólogo, una vez que los interlocutores deciden definir al sofista y se topan con el problema del no ser, proclaman la necesidad de contravenir el dictum parmenídeo y, por ende, la de combinar el ser con el no ser. Entonces, presentan tres hipótesis sobre la combinación de los géneros, rechazan las dos primeras, aceptan la tercera de ellas (según la cual algunos se combinan con otros) y se preguntan por la ciencia encargada de mostrar qué "géneros" ( $\gamma \varepsilon ́ v \eta, 253 b 8)$ se combinan y cuáles no. En ese punto, el Extranjero pregunta a Teeteto si acaso "sin darnos cuenta ( $\dot{\lambda} \alpha \dot{\theta} \theta o \mu \varepsilon v)$... hemos encontrado al filósofo" (253c6-9). Y luego, al presentar la ciencia dialéctica como

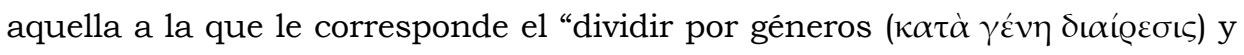
no considerar que una misma Forma es diferente, ni que una diferente es la

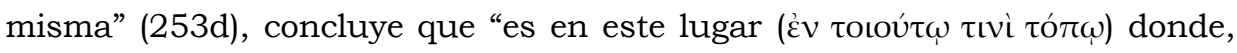
tanto ahora como más adelante, encontraremos al filósofo -si lo buscamos -" (253e) ${ }^{19}$. La insinuación del Extranjero respecto de la posibilidad de haber ignorado el descubrimiento del filósofo puede parecernos extraña si tenemos

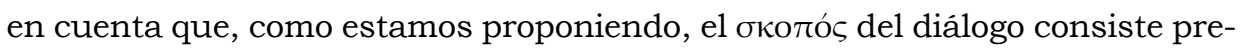
cisamente en la demostración de su condición filosófica. No obstante, nada en los diálogos platónicos parece pasarle inadvertido al interlocutor principal y esa sorpresa del Extranjero, según pensamos, es más bien fingida. De hecho, al comienzo de la obra, el mismo personaje se asombra de las similitudes entre las figuras del pescador con caña y del sofista (221d8-9) cuando, en realidad, resulta evidente que la elección de la primera es premeditada ${ }^{20}$. En definitiva,

\footnotetext{
19 Seguimos aquí la traducción propuesta por Dixsaut, M., o.c., p. 215.

20 Nótese que, en ambos casos, el Extranjero invoca a los dioses: al hablar del pescador y el sofista: "Pero, ipor los dioses! ¿ignoraremos, acaso, que los dos hombres están emparentados?" (221d8-9) y luego al presentar la dialéctica: "O acaso sin darnos cuenta hemos caído, por Zeus, en la ciencia de los hombres libres y buscando al sofista, corremos el riesgo de haber encontrado primero al filósofo" (253c6-9).
} 
si en ese primer caso la elección del pescador no es azarosa, tampoco ahora la aparición del filósofo parece ser un suceso fortuito y la frase con la que concluye el pasaje lo confirma. Retomando de manera explícita el mismo término con el que Sócrates lo había cuestionado al comienzo de la obra, el Extranjero afirma que es en ese "lugar" (i.e. el de la dialéctica) donde siempre se encontrará al filósofo "si lo buscamos ( $\dot{\alpha} \alpha \nu \zeta \eta \tau \tilde{\omega} \mu \varepsilon v)$ " (253e). Esta cláusula final -que algunos interpretan como el anticipo de un diálogo titulado Filósofo (y, en ese sentido, traducen como "cuando lo busquemos")-21 estaría indicando que la aparición del filósofo no ocurrirá en un futuro determinado, sino que, entendiendo que su lugar es la dialéctica, toda vez que esta técnica sea empleada el filósofo aparecerá ${ }^{22}$.

Aun cuando críticos como Cornford supongan que la búsqueda del filósofo es solo una promesa incumplida en el diálogo ${ }^{23}$, aquí pensamos que esa figura se revela por medio de la ejecución de su actividad esencial justamente en el pasaje que estamos estudiando. En esas líneas, y gracias a una absoluta auto-conciencia de los quehaceres que lo definen, el Extranjero responde el cuestionamiento de Sócrates. Si en el prólogo, Sócrates le había solicitado que,

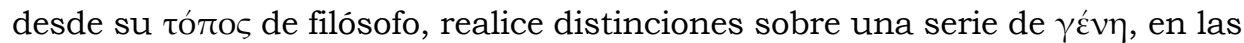
líneas que citamos, el Extranjero finalmente delimita el tó prepara el terreno para ejecutar distinciones sobre otra serie de $\gamma \varepsilon \dot{v} \eta$. Ahora bien, ni los $\gamma \varepsilon ́ v \eta$ que se individualizarán ni las distinciones que se realizarán sobre ellos en los pasajes siguientes del diálogo son de la misma naturaleza que aquellas que Sócrates presenta y el Extranjero ejecuta en los pasajes dedicados a la caracterización del sofista. Por esta razón, en el siguiente apartado intentaremos echar luz sobre las vinculaciones entre los distintos $\gamma \dot{v} v \eta$ (el sofista, por un lado y los géneros mayores, por el otro) y las distintas técnicas (el procedimiento de la división y el método dialéctico).

\footnotetext{
${ }^{21}$ Sobre la premeditación en la elección del modelo del pescador, véase Cordero, N.L., Platón, El Sofista, p. 435, n. 224.

${ }^{22}$ Al respecto, véase Dixsaut, M., o.c., p. 215. Por otro lado, consúltese Fronterotta, F., Platone. Sofista, Milán: BUR, 2007, p. 418, n. 223, para quien esa cláusula y la que aparece luego cuando el Extranjero señala, respecto del filósofo, que "nos ocuparemos de él con mayor claridad, si aún lo deseamos" (254b4), resultan irónicas o bien porque ya en esas líneas emerge el perfil del filósofo o bien porque se verá que no es posible producir una definición del ese filósofo como la que se ofreció del sofista.

${ }^{23}$ Cf. Cornford, F.M., Plato's Theory of Knowledge, Londres: Routledge \& Kegan Paul, 1935 (citamos según la traducción española de Cordero, N. y M.D. del C. Ligatto, La teoría platónica del conocimiento, Buenos Aires: Paidós, 2007, p. 330).
} 
En el apartado anterior, observamos que en el prólogo del diálogo Sofista la discusión entre Sócrates, Teodoro y el Extranjero de Elea deja entrever que el бкотós de la obra consiste en la demostración, por parte de este último, de su condición filosófica. No obstante, ni bien el Extranjero comienza a demostrar ese estatus, plantea otro бкото́s. Advirtiendo que la tarea de distinguir al filósofo, al sofista y al político no es sencilla, dicho personaje -por un pedido expreso de Sócrates- elige un interlocutor, que no es otro que Teeteto, y es a este a quien le comunica que "primero debemos investigar en común, tú y yo, comenzando ahora, según me parece, por el sofista, con el objeto de buscar y de demostrar, mediante una definición, qué es" (218b-c). Ocurre entonces como si en un primer nivel del diálogo, el objetivo fuera revelar el perfil del filósofo $y$, en un segundo nivel, el de caracterizar al sofista ${ }^{24}$. En este sentido, una vez establecido ese par de niveles con sus respectivos бколоí, cabe preguntarse por el tipo de relación que guardan entre ellos y, en particular, por la función que cumple la definición del sofista en el plan general que busca hacer ostensible el perfil del filósofo. Y según intentaremos evidenciar, la definición del sofista no representa un objetivo independiente de aquel planteado en el prólogo. Por el contrario, por medio de esa figura y de las distinciones que se operan para definirla, el Extranjero sienta las bases de la tarea que ejecutará con vistas a justificar su debatida condición.

Ahora bien, la función que le adjudicaremos a la figura del sofista y la relación entre los diferentes бко тó́ solo pueden comprenderse a través de la noción de $\pi \alpha \varrho \alpha ́ \delta \varepsilon \imath \gamma \mu \alpha$. Este término, formado por el prefijo $\pi \alpha \varrho \alpha ́$ ("delante") y el sustantivo $\delta \varepsilon \tilde{i} \gamma \mu \alpha$ ("patrón"), puede traducirse como "ejemplo" o "modelo", en cuanto un $\delta \varepsilon \tilde{\varepsilon} \gamma \mu \alpha$ se ubica delante de algo para servirle de modelo ${ }^{25}$. En el corpus platonicum, dicho término es utilizado, en primer lugar, para señalar una relación ejemplar entre dos objetos cualesquiera. Así, en el Fedro, Sócrates sostiene que los discursos sobre el amor que se han pronunciado representan un "ejemplo" ( $\pi \alpha \varrho \alpha ́ \delta \varepsilon \gamma \gamma \mu \alpha, 262 \mathrm{~d} 1)$ de cómo un orador puede desorientar a los

\footnotetext{
${ }^{24}$ De forma similar a los niveles que estamos planteando, Gomperz, T., Griechische Denker. Eine Geschichte der antiken Philosophie, Leipzig: Veit \& Co, 1896-1909 (citamos según la traducción italiana de Bandini, L., Pensatori Greci. Storia della filosofia antica, v. II, Firenze: La Nuova Italia Editrice, 1933-1950, p. 503), utiliza una metáfora del fruto y la cáscara para hablar de la estructura del diálogo Sofista. Para el crítico francés, el fruto sería la demostración de la posibilidad del error y la cáscara las definiciones del sofista.

${ }^{25}$ Sobre los sentidos generales del término, Cf. LSJ, s.v. ' $\pi \alpha \varrho \alpha ́ \delta \varepsilon \iota \gamma \mu \alpha$ '.
} 
oyentes $^{26}$. En segundo lugar, el término se utiliza para ilustrar ciertas características de las Formas. En la República, Sócrates sugiere que los futuros filósofos gobernantes deberán servirse del "bien en sî" como un "modelo" ( $\pi \alpha \varrho \alpha ́ \delta \varepsilon \imath \gamma \mu \alpha$, 540a9) para organizar el Estado, los particulares y a sí mismos, mientras que en el Parménides, el Joven Sócrates sugiere que las Formas son como "modelos" $(\pi \alpha \varrho \alpha \delta \varepsilon \dot{\gamma} \gamma \mu \alpha \tau \alpha, 132 \mathrm{~d} 1)$ de las otras cosas que solo se le parecen. Por último, en los diálogos Sofista y Político y en contextos eminentemente dialécticos, el término es utilizado para señalar un objeto que se incorpora en el umbral de una determinada investigación con el fin de preparar el terreno para el examen del objeto principal de la misma ${ }^{27}$. Estudiando este último uso, Goldschmidt ha demostrado que esos $\pi \alpha \varrho \alpha \delta \varepsilon \dot{\gamma} \gamma \mu \alpha \tau \alpha$ cumplen con dos funciones: a) habitúan al inexperto en el método que luego se aplicará sobre el objeto principal y b) ofrecen similitudes entre ambos objetos, similitudes que permiten ubicar el objeto principal dentro de una estructura ${ }^{28}$.

En el diálogo Sofista, los $\pi \alpha \varrho \alpha \delta \varepsilon \hat{\gamma} \gamma \mu \alpha \tau \alpha$ se incorporan cuando el Extranjero advierte que la tarea de definir al sofista no es sencilla y entonces sugiere practicar el "método" ( $\mu \varepsilon ́ \theta o \delta o s, 218 d 5)$ que los conducirá a aquella definición, ocupándose de un caso sencillo que funcione como "modelo" ( $\pi \alpha \varrho \alpha ́ \delta \varepsilon \nvdash \gamma \mu \alpha, 218 d 9)$ de algo más grande. Ese caso es el del pescador con caña, que el Extranjero selecciona de forma premeditada (218e). Por otro lado, el método elegido es el de la división dicotómica que consiste en el cumplimiento, sobre un determinado género, de una serie de sucesivos cortes transversales que van separando especies con características contrarias hasta alcanzar la definición de una especie en particular. En este sentido, algunos críticos han supuesto que el propósito de este procedimiento es, justamente, el de aclarar

\footnotetext{
${ }^{26}$ Pueden citarse además los casos de Apol. 23b1 y Fil. 13c8. Al respecto, véase Patterson, R., Image and Reality in Plato's Metaphysics, Indianapolis: Hackett Publishing Company, 1985, pp. 12-13.

${ }^{27}$ Sobre el uso de $\pi \alpha \varrho \alpha \delta \varepsilon\{́ \gamma \mu \alpha \tau \alpha$ en los diálogos Sofista y Politico, véase especialmente Kato, S., "The Role of Paradeigma in the Statesman", en: Rowe, C. (ed.), Reading the Statesman, Sankt Augustin: Academia Verlag, 1995, pp. 162-72; Rosen, S., Plato's Statesman: the Web of Politics, New Haven: Yale University Press, 1995; Lane M.S., Method and Politics in Plato's Statesman, Cambridge: CUP, 1998; Gill, M.L., "Models in Plato's Sophist and Stateman", en: Plato, 6, 2006 (http://gramata.univ-paris1.fr/Plato/article27.html, consultado el 14 de agosto de 2014); El Murr, D., "Paradigm and diairesis: a response to M.L. Gill's 'Models in Plato's Sophist and Statesman”, en: Plato, 6, 2006 (http://gramata.univ-paris1.fr/Plato/article63.html, consultado el 14 de agosto de 2014).

${ }^{28}$ Goldschmidt, V., Le paradigme dans la dialectique platonicienne, París: Presses Universitaires, 1947, pp. 23-26.
} 
el significado de esa infima especie ${ }^{29}$. Suponiendo que el pescador con caña es un "técnico" (tekhnítes, 219a5), los interlocutores dividen el género superior de la $\tau \varepsilon ́ \chi v \eta$ en dos partes: la de la técnica productiva y la de la adquisitiva. A su vez, esta última es dividida en adquisición por intercambio mutuo y por captura; la captura es dividida en disputa y caza; la caza, entre la que se ocupa de los seres inanimados y aquella que hace lo propio con los animados, mientras que los seres animados son divididos en terrestres y nadadores (219a-220a). Si bien la división continúa una serie de pasos, a esta altura del procedimiento ya puede verse con claridad el lugar que le corresponde al pescador con caña: el de un técnico cazador de animales nadadores.

Una vez concluida esa división, el Extranjero propone hallar la definición del sofista según el $\pi \alpha \varrho \alpha ́ \delta \varepsilon \uparrow \gamma \mu \alpha$ (221c5) del pescador y entonces advierte que dicho pescador y el sofista están emparentados. Ambos se manifiestan como cazadores, uno de animales que habitan el agua, el otro de criaturas terrestres llenas de riqueza (221d-222a). Llegados a este punto, es posible confirmar que la incorporación del $\pi \alpha \varrho \alpha ́ \delta \varepsilon \iota \gamma \mu \alpha$ ha cumplido con las dos funciones señaladas: la práctica del método y la explicitación de similitudes entre los objetos en cuestión. El objeto "menor" (en este caso, el pescador con caña) ha operado como un modelo a pequeña escala del objeto "mayor" (el sofista). No obstante, lo que ahora intentaremos sostener es que la misma figura del sofista podría estar funcionando, implícitamente, como una especie de nuevo $\pi \alpha \varrho \alpha ́ \delta \varepsilon \imath \gamma \mu \alpha$. En efecto, su definición a) exige un verdadero ejercicio del procedimiento de la división que la caracterización del pescador apenas había permitido y b) presenta una serie de similitudes con el objeto mayor de la discusión. A continuación desarrollamos ambos puntos.

\section{a. La definición del sofista y el ejercicio de la dialéctica}

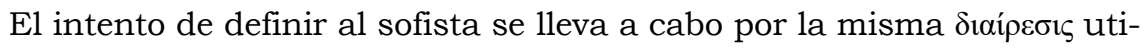
lizada para definir al pescador. Aunque en el diálogo no se formula ninguna restricción teórica, en la práctica, las siete definiciones del sofista se ajustan a relaciones entre especies y géneros y las divisiones suelen ser dicotómicas ${ }^{30}$.

\footnotetext{
${ }^{29}$ Véase Li Carrillo, V., "Las definiciones del sofista”, en: Episteme, 1261 (1959-1960), pp. 83-184, p. 176. En la misma linea, Philip, J., "Platonic Diairesis", en: Transactions and Proceedings of the American Philological Association, v. XCVII (1966), pp. 335-358, pp. 348-349, sugiere que el

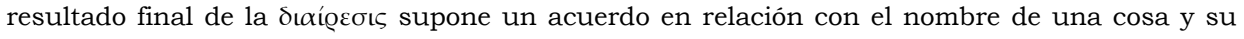
definición, i.e. la explicitación de sus características y función esenciales.

${ }^{30}$ Al respecto, véase Ionescu, C., "Dialectic in Plato's Sophist: Division and the Communion of Kinds”, en: Arethusa, v. XLVI, 1 (2013), pp. 41-64, p. 44. Téngase en cuenta que el género de la técnica termina dividido en tres partes: adquisición, producción y separación (226c). En el Filebo
} 
Ahora bien, si lo que buscamos probar es que, en la estructura global del diálogo, esa caracterización representa una especie de ejercicio propedéutico, entonces debemos identificar para qué tipo de habilidades nos entrena el procedimiento divisorio.

Ante todo, debe advertirse que el grupo de términos relativos al campo semántico de la división aparece en varios segmentos del diálogo. Ya en el pró-

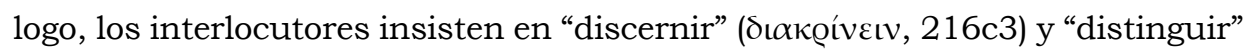

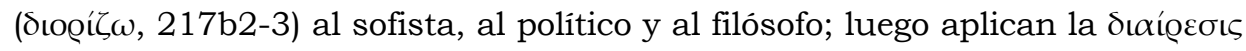

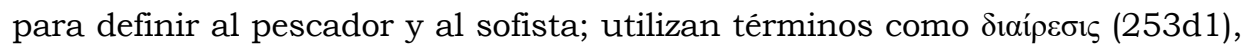

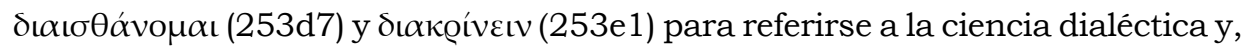

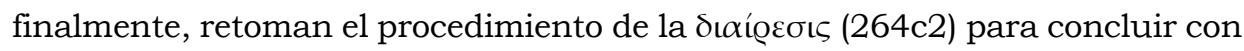
la definición del sofista. Teniendo estas apariciones, es posible clasificar dos usos de la división: uno vinculado a la definición y el otro ligado a la dialéctica. A continuación, intentaremos interpretar el primero como un ejercicio destinado a preparar el terreno para la ejecución de la ciencia dialéctica.

Como observamos, en el corazón mismo del diálogo, el Extranjero pregunta si no le corresponde a la ciencia dialéctica el "dividir por géneros ( $\kappa \alpha \tau \grave{\alpha}$

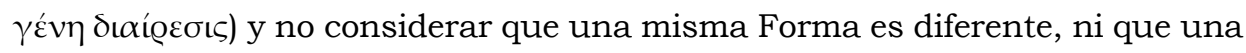
diferente es la misma" (253d1-2) y, en las siguientes líneas, añade dos usos del

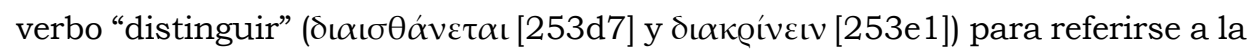
capacidad de discernir "respecto de los géneros, cómo algunos son capaces de comunicarse con otros, y cómo no" (253d9-e2). El pasaje 253d1-e2 ha generado enormes controversias entre los comentadores del diálogo, pero aquí solo nos concentraremos en las discusiones que atañen a la vinculación entre división y dialéctica. Dado que al describir los quehaceres de la dialéctica en 253d1-2 el Extranjero apela a términos relacionados con la división, los intérpretes han supuesto o bien que división y dialéctica se asimilan, o bien que ambas resultan inconexas o bien que la primera es una condición necesaria, pero no suficiente para la ciencia dialéctica ${ }^{31}$. Aquí nos inclinaremos por esta última alternativa,

(16d) y el Fedro, Sócrates habla de dividir las ideas siguiendo sus "naturales articulaciones" (265e1-2). Sobre las diferencias entre la división presentada en Fedro y aquella practicada en Sofista, véase Santa Cruz, M.I., "Division et dialectique dans le Phèdre", en: Rossetti, L. (ed.), Understanding The Phaedrus, Sankt Augustin: Academia Verlag, 1992.

${ }^{31}$ Entre los defensores de la primera opción, véase Stenzel, J., Studien Zur Entwicklung Der Platonischen Dialektik Von Sokrates Zu Aristoteles, Leipzig: 1931 (citamos según la traducción inglesa de Allan, D.J., Plato's Method of Dialectic, Nueva York: Clarendon Press, 1940, pp. 96-108); Cornford, o.c., pp. 330-332; Lloyd, A.C., "Plato's description of Division", en: Classical Quarterly. New Series, 2 (1954), pp. 105-112, p. 110 y Bluck, R., Plato's Sophist. A commentary, pp. 126-127; de la segunda, con diversos matices, véase Philip, J., o.c., pp. 348-350; Trevaskis, J., "Division 
teniendo en cuenta que las posiciones que postulan una identificación total o una distinción radical se enfrentan a dificultades insuperables. Por un lado, la dialéctica no puede asimilarse a la división, pues en los quehaceres enumerados en nuestro pasaje no se hace referencia alguna a las características esenciales del procedimiento practicado antes: ni a las divisiones dicotómicas o tricotómicas, ni a la división de un género en sus respectivas especies, ni a la definición con la que suele concluir el procedimiento, ni a las reglas que lo gobiernan $^{32}$. Por otro lado, la distinción radical entre división y dialéctica no solo es contradicha por el vocabulario que aparece en el pasaje de Sofista, sino además -como ya veremos- por ciertos razonamientos de Político.

Debido a los argumentos expuestos, la dialéctica no puede equipararse con la división, pero tampoco puede diferenciarse por completo de ella. Entonces,

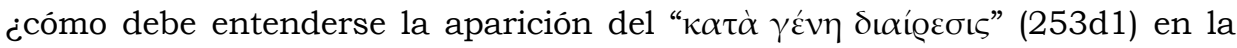
descripción de dicha ciencia? A pesar de que la tarea de la dialéctica no es la de alcanzar ningún definiendum ni establecer una estructura jerárquica de géneros y especies, sí lo es la de dividir, en el sentido de distinguir o separar un género de otro con el fin de no confundirlos ${ }^{33}$. De hecho, el mismo término

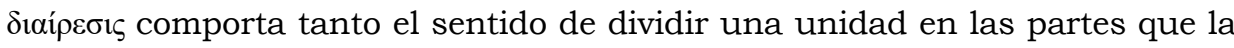
componen como también el de separar a unas cosas de otras; por ejemplo, en el campo musical, separar los diferentes sonidos ${ }^{34}$. En este sentido, la dialéctica parece fundarse en esa capacidad de separar o distinguir, capacidad que ha sido practicada largamente por el Extranjero y Teeteto en otra esfera y con otros objetivos ${ }^{35}$. Ejercitar la división -ese singular procedimiento que trata de explicitar disimilitudes entre diferentes objetos- representaría el mejor preámbulo antes de distinguir entre las Formas que son y aquellas que no son

and Its Relation to Dialectic and Ontology in Plato", en: Phronesis, v. XII, 2 (1967), pp. 118-129, p. 120; Ryle, G., Plato's Progress, Cambridge: CUP, 1966, pp. 139-141 y Rosen, S., Plato's Sophist. The Drama of Original and Image, p. 259; de la última opción, véase la traducción de Cordero, N., El Sofista, p. 433.

32 Cf. Gómez-Lobo, A., "Plato's Description of Dialectic in the Sophist 253d1-e2", en: Phronesis, v. XXII, 1 (1977), pp. 29-47, pp. 33-36, quien sostiene que, en el pasaje que estamos estudiando, no aparece la metáfora de una pirámide con sus movimientos ascendentes y descendentes y sus géneros superiores e inferiores que parecen caracterizar la división. Sobre esas metáforas, véase Stenzel, J., o.c., pp. xxxii y 104. Además, consúltese Ionescu, C., o.c., p. 55.

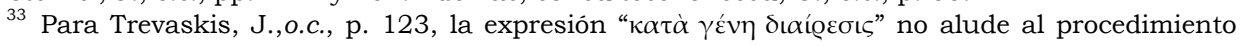
divisorio, sino a una distinción entre conceptos.

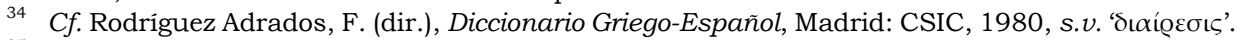
35 Cf. De Chiara-Quenzer D., "The Purpose of the Philosophical Method in Plato's Statesman, en: Apeiron, v. XXXI, 2 (1998), pp. 91-126, p. 119, n. 39, quien nota esas diferencias entre los dos usos de la división y Fronterotta, F., Platone. Sofista, Milán: BUR, 2007, p. 416, n. 221, para quien la dialéctica termina abrigando la división. 
capaces de comunicarse con otras. Resulta evidente que la división ejercitada en la caracterización del sofista no es del mismo tipo que aquella que se utiliza en el marco de la ciencia dialéctica. Sin embargo, si consideramos que, en un principio, Sócrates le solicita al Extranjero que hable desde su lugar de filósofo estableciendo una serie de distinciones y luego, en el corazón del diálogo, el mismo Extranjero sostiene que el lugar del filósofo es la dialéctica y que esta consiste en establecer distinciones, es claro que la capacidad de dividir y distinguir representa un aspecto esencial del quehacer filosófico ${ }^{36}$.

Ahora bien, más allá del Sofista, la vinculación entre división y dialéctica es tematizada en diálogos como el Fedro y el Político. Si bien es cierto que el procedimiento divisorio que aparece en el Fedro no comparte los mismos rasgos

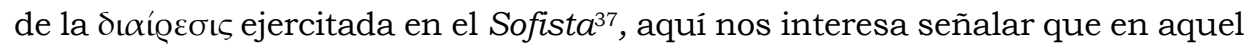
diálogo la capacidad de dividir parece representar una mera herramienta. En tanto medio que funda el "hablar y pensar" (

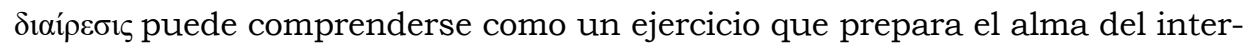
locutor para la verdadera dialéctica ${ }^{38}$. Por otro lado, en el Político, reflexionando sobre las razones por las que se ha emprendido -a través de la división- la definición de la figura que le da nombre al diálogo, el Extranjero pregunta si “¿es por el político mismo por lo que nos la hemos propuesto o, más bien, para hacernos más hábiles dialécticos en todo tipo de cuestiones?” (285d4-6). Ante ello, su interlocutor, el Joven Sócrates, responde que lo han hecho por la segunda opción. Mientras que el lector podría suponer que el objetivo es definir al político, los interlocutores son conscientes de que el objetivo central es, en realidad, otro: el de hacerse más hábiles dialécticos. Entonces, debemos preguntarnos: ¿qué es lo que, particularmente, los hace más hábiles?

Si tenemos en cuenta la variedad de recursos utilizados en el diálogo -divisiones, mitos, paradigmas-39, la respuesta podría ser dificultosa, pero lo cierto

\footnotetext{
${ }^{36}$ Cf. Ackrill, J.L., "In Defence of Platonic Division", en: Wood O. y G. Pitcher (eds.), Ryle: A Collection of Critical Essays, Londres: Macmillan, 1970, pp. 373-392 (citamos según Ackrill, J.L., "In Defence of Platonic Division", en: Ackrill, J.L. (ed.), Essays on Plato and Aristotle, Oxford: OUP, 1997, pp. 93-109, p. 107), quien se encarga de hacer una férrea defensa del procedimiento divisorio.

${ }^{37} C f$. Santa Cruz, M., "Division et dialectique dans le Phèdre”, p. 255, quien señala que en el Fedro no aparecen las divisiones dicotómicas, ni el objetivo de definir y que, además, se insiste no solo en la división, sino también en la reunión.

${ }^{38}$ Cf. Griswold, C.L., Self-Knowledge in Plato's Phaedrus, New Haven: Pennsylvania State University Press, 1986, p. 183 y Santa Cruz, M.I., o.c., p. 255.

39 Los interlocutores utilizan la división para definir al político (258b7-267a) y luego apelan al relato mítico y al $\pi \alpha \rho \alpha ́ \delta \varepsilon i \gamma \mu \alpha$. Por medio de este último, se introduce el arte de tejer que, luego de un primer intento, es definido de manera satisfactoria al retomar la división. Entonces, gracias a
} 
es que la unidad misma del Politico descansa sobre la división. Existe un único procedimiento divisorio que, incluso siendo interrumpido, atraviesa de principio a fin la estructura de la obra ${ }^{40}$. Es más, esas interrupciones se vinculan con la propia división, ya que el mito viene a corregir los primeros resultados fallidos de este procedimiento y el uso del paradigma supone, en realidad, un proceso complementario al de la división que se apoya en los resultados obtenidos y sienta las condiciones para la caracterización definitiva del político por medio

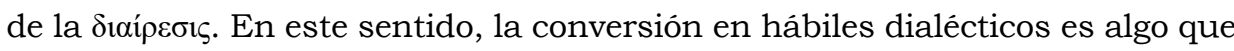
debe verse a partir de la pregunta del Extranjero en 285d4-6 tanto retrospectiva como prospectivamente. Los interlocutores comienzan a convertirse en mejores dialécticos desde las primeras divisiones y terminan de hacerlo hacia el final de la búsqueda, lo que les otorga el conocimiento no solo de los errores cometidos, sino también del procedimiento acertado para encontrar la figura del político. Si bien apelamos al diálogo Político con el objeto de observar las vinculaciones entre división y dialéctica, lo cierto es que los supuestos y las consecuencias del argumento que acabamos de estudiar podrian ayudarnos a reafirmar nuestras hipótesis sobre el diálogo Sofista. A partir de la pregunta formulada en el Político sobre los objetivos del diálogo, podríamos pensar que ambas definiciones (la del político y la del sofista) se encuentran subordinadas a un propósito principal que aparece, en ambas obras, vinculado al filósofo y a la tarea que lo define: la dialéctica.

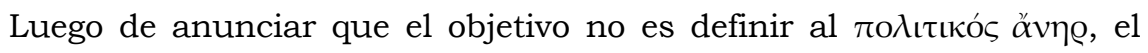
Extranjero afirma que ningún hombre razonable hubiese aceptado buscar la definición del arte de tejer (arte propuesto como modelo del arte político) por él mismo (285d8-9). Acto seguido, sugiere que a la mayoría le pasa inadvertido que algunas realidades comportan similes sensibles fáciles de comprender, mientras que de las realidades más "altas y valiosas" ( $\mu \varepsilon ́ \gamma \iota \sigma \tau \alpha \iota ~ \kappa \alpha i ̀ ~ \tau \iota \mu \iota \omega ́ \tau \alpha \tau \alpha \iota$, $285 \mathrm{e} 4)$, de las realidades "incorpóreas" ( $\alpha \sigma \omega \mu \alpha \tau \alpha, 286 a 5)$, "no hay imagen alguna nítidamente adaptada a los hombres" (286a). Por lo tanto, añade, hay que ejercitarse para poder dar y recibir razón de cada una de ellas, pues es a ellas "a las que apunta todo lo dicho hasta el momento" (286a5-7), aunque resulta más sencillo "practicar con objetos pequeños". Por último, el Extranjero vincula explícitamente los argumentos del Politico y del Sofista, en lo relativo

\footnotetext{
las distinciones establecidas en dicha división, se reinicia la definición del político (287a7 ss.) y se

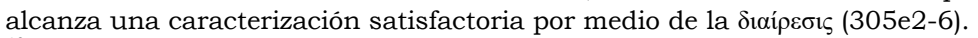

40 Cf. El Murr, D., "La division et l'unité du Politique de Platon", en: Les Études philosophiques, 74 (2005), pp. 295-324, p. 303.
}

ARETÉ Revista de Filosofía, vol. XXVIII, N² 2, 2016 / ISSN 1016-913X 
a las largas exposiciones (286b7-c3). De los razonamientos expuestos, tres cuestiones merecen especialmente nuestra atención: en primer lugar, la referencia a los objetivos del diálogo; en segundo lugar, la relación entre los símiles sensibles y las realidades incorpóreas y, en tercer lugar, la analogía establecida entre los argumentos del Politico y del Sofista.

En relación con la primera observación, aquí entendemos que su advertencia sobre la definición del arte del tejido debe entenderse en el con-

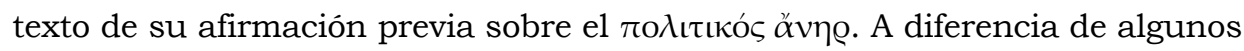
intérpretes para quienes las palabras del Extranjero plantean un contraste tácito entre tejido y política (contraste según el cual solo la definición de la última tendría sentido en sí misma) ${ }^{41}$, nosotros entendemos que, anticipando eventuales cuestionamientos por haber relegado la definición del político, el personaje platónico está insinuando que si ningún hombre razonable hubiese aceptado definir el arte de tejer por sí mismo, tampoco debería hacerlo con el

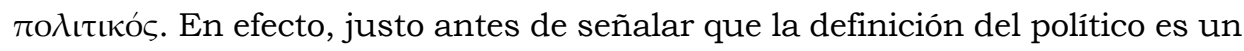
objetivo secundario, el mismo Extranjero retoma el $\pi \alpha \rho \alpha ́ \delta \varepsilon \gamma \gamma \mu \alpha$ de los niños que aprenden las primeras letras para sugerir que el propósito de ese aprendizaje no es resolver un único problema (i.e. ni las letras en sílabas breves y fáciles ni las letras en sílabas largas y dificiles), sino hacerlos hábiles en cuestiones de gramática para resolver todo posible problema ${ }^{42}$. Por lo tanto, si ponemos en paralelo ese $\pi \alpha \rho \alpha ́ \delta \varepsilon \imath \gamma \mu \alpha$ y el tratamiento del tejido y la política, deberíamos concluir (como de hecho lo hace el Extranjero) que la práctica sobre el caso del tejido y sobre el caso del político no se realizan para resolver esos problemas particulares, sino para tornarse dialécticos más hábiles en todo tipo de cuestiones. En este sentido, es posible establecer un paralelo con el Sofista y afirmar que, en este diálogo, ningún hombre razonable debería pensar tampoco que las definiciones del pescador y del sofista se buscan por ellas mismas. Si en un caso los interlocutores afirman que la definición del político se hace con fines dialécticos, en el otro estarian dejando entrever que la definición del sofista se lleva a cabo con fines filosófico-dialécticos: para ejercitar distinciones y para exhibir el perfil filosófico del Extranjero.

La segunda cuestión que queríamos examinar aquí es la diferenciación entre las realidades que cuentan con símiles sensibles fáciles de comprender y

\footnotetext{
${ }^{41}$ Cf. Miller, M., The Philosopher in Plato's Statesman, Las Vegas: Parmenides Publishing, 2004, pp. 69-70 y White, D., Myth, Metaphysics and Dialectic in Plato's Statesman, Chippenham: Ashgate Publishing Limited, 2007, p 73.

${ }^{42}$ Pol. 285c10-d2.
} 
aquellas que no cuentan con similes nítidos adaptados a los hombres. Dado que Platón no especifica los casos propios de cada grupo, podría suponerse, como creen algunos intérpretes, que el arte del tejido es un ejemplo de las primeras y el arte político un ejemplo de las últimas, ${ }^{43}$ pero esta lectura se enfrenta con una dificultad. En el argumento del diálogo, el arte del tejido parece representar un simil sensible y nítido mediante el cual se busca explicar el arte político, lo que pondría en duda el estatus de este último como una realidad que no cuenta con dichos similes. Consciente de esta dificultad, Sayre supone que el tejido guarda un tipo de similitud con el arte político que solo puede evidenciarse

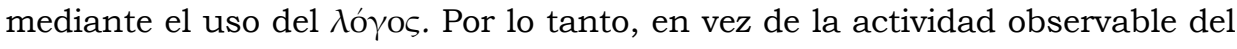
tejido, sería el discurso el que estaría proporcionando, en sentido estricto, el paradigma con el que se persigue el arte politico ${ }^{44}$. Sin embargo, existe otra interpretación posible que aquí defenderemos, interpretación que cuenta con una serie de presupuestos.

Debe considerarse, en primer lugar, que el Extranjero -justo antes de presentar los dos grupos de realidades- subordinó la búsqueda del político a la transformación en hábiles dialécticos. En segundo lugar, que -luego de esa propuesta- el mismo Extranjero añade que todo lo dicho apunta hacia las realidades más altas y valiosas. En tercer lugar, que esas realidades pueden ser leídas, siguiendo la exégesis de Kahn, como las Formas presentadas en los

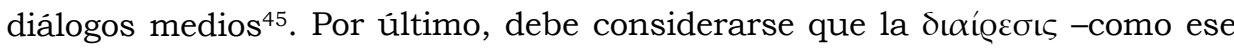
procedimiento previo a la dialéctica por medio del cual se define al político- no

\footnotetext{
${ }^{43}$ Así piensan, por ejemplo, White, D., o.c., p. 90 y Gill, M.L., "Method and Metaphysics in Plato's Sophist and Statesman", en: Zalta, E. (ed.), The Stanford Encyclopedia of Philosophy (http:// plato. stanford.edu/archives/win2009/entries/plato-sophstate), 2015. Particularmente, White, D., o.c., p. 92, sostiene que el tejido puede aprenderse mediante la observación porque su producción y resultados son de naturaleza material, mientras que el arte de gobernar supone un ejercicio abstracto que no puede ser observado.

${ }^{44}$ Cf. Sayre, K., Metaphysics and Method in Plato's Statesman, Nueva York: CUP, 2006, pp. 85-86. 45 Cf. Kahn, C., "The Place of the Statesman in Plato's Later Work", en: Rowe, C. (ed.), Reading the Statesman, Sankt Augustin: Academia Verlag, 1995, pp. 49-60, pp. 56-57. Siguiendo la misma línea, otros intérpretes han vinculado ese pasaje del Politico con uno del Fedro en donde Sócrates también habla de realidades valiosas (250b-c). Al respecto, véase Gulley, N., "Plato's Theory of Recollection", en: The Classical Quarterly, New Series, v. IV, 3/4 (1954), pp. 194-213, p. 202 y Benardete, S., The Being of the Beautiful. Plato's Theaetetus, Sophist and Statesman, Chicago: Chicago University Press, 1984, III, p. 154. Por otro lado, Owen, G.E.L., "Plato on the Undepictable", en: Nussbaum, M. (ed.), Logic, Science and Dialectic: Collected Papers in Greek Philosophy, Londres: Duckworth, 1986, p. 61, niega la continuidad entre los seres incorpóreos del Politico y las Formas de los diálogos medios, afirmando que en el pasaje del Político, Platón solo esboza distinciones lógicas, epistemológicas y lingüísticas.
} 
trata, ni en este diálogo ni en el Sofista, con aquellas Formas ${ }^{46}$. Por lo tanto, puede suponerse que el político no representa una de las realidades más valiosas e incorpóreas (como tampoco lo hace el sofista en el diálogo homónimo) ${ }^{47}$, sino que, por el contrario, lo dicho a propósito de ella apunta hacia la dialéctica y hacia los objetos de esa dialéctica. En este sentido, Lane sugiere que, en el

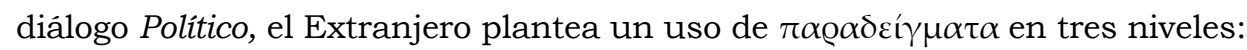
en el primero, el aprendizaje de las letras por parte de los niños representa el paradigma de los paradigmas; en el segundo nivel, el tejido sirve como paradigma de la política y, en el último nivel, la política -siendo una de las realidades "grandes" (277d2, 278e7-8)- estaría ejemplificando realidades aun más grandes $^{48}$. Asimismo, Lane sostiene que el $\lambda$ ó $\gamma$ o que busca definir el arte de gobernar es una aproximación, un juego de niños, en comparación con el $\lambda$ ó $\gamma$ $\varsigma$ realmente dificultoso dedicado a las realidades más valiosas ${ }^{49}$.

Finalmente, el último punto de la intervención del Extranjero que deseábamos señalar es el trazado del paralelo entre los argumentos del Sofista y del Politico. En efecto, para ejemplificar el tedio que causa la extensión de ciertas exposiciones, ese personaje cita los casos del tejido y del mito presentes en

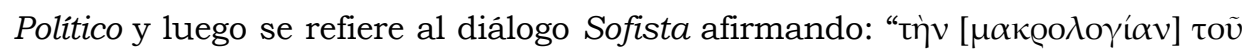

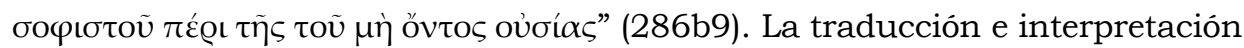
de esta línea, según sostiene Lacey, descansa sobre la acentuación de la preposición, pues si ella aparece como $\pi \varepsilon \mathrm{Q}^{50}$, la larga discusión vendría a ser aquella dedicada a tò $\mu$ ò óv (y así parecen entenderlo algunos traductores) ${ }^{51}$,

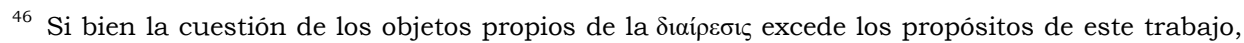
cabe mencionar que Cherniss, H., The Riddle of the Early Academy, Nueva York: Russell \& Russell, 1962, pp. 54-55, afirma que, en el diálogo Sofista, Platón no prevé ningún esquema divisorio que exprese una jerarquía ontológica de las Formas, pues, de hecho, no piensa en un ámbito eidético organizado de esa manera. Por otro lado, Philip, J., o.c., p. 358, advierte que en

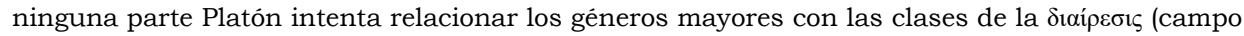
de entrenamiento del dialéctico), mientras que Trevaskis, J., o.c., p. 128, sostiene que la división no trata con Formas y que las definiciones del sofista en el diálogo homónimo no tienen relación alguna con ellas. Por su parte, Ackrill, J., o.c., p. 109, piensa que la dialéctica, como el estudio de las interrelaciones entre las Formas, es algo mucho más rico que la división en clases, aunque la diferencia no es insalvable.

${ }^{47}$ Al respecto, $c f$. Trevaskis, J., o.c., pp. 125-26, para quien ni el sofista ni la sofistica conforman una Idea. Por otro lado, véase Cornford, F., o.c., pp. 235-238 y Moravcsik, J.M.E., "The Anatomy of Plato's Divisions", en: Exegesis and Argument, Phronesis Suppl., I (1973), pp. 324-348, pp. 329-343, quienes suponen que la sofistica sí representa una Idea.

48 Cf. Lane, M.S., o.c., p. 62.

49 Ibid., pp. 62-63, n. 86.

50 Cf. Duke, E.A. y otros, Platonis Opera, recognoverunt brevique adnotatione critica instruxerunt, t. I, Oxford: OUP, 1995, p. 520.

${ }^{51}$ Cf. Maria Inés Santa Cruz (Platón, Político, Santa Cruz, M.I. (trad.), en: Diálogos V, Madrid: Gredos, 1988), por ejemplo, traduce: "el tedio que nos causaron la larga exposición sobre el
} 
pero, en cambio, si se acentúa пćp1 $1^{52}$, la exposición extensa sería la relativa al sofista (exposición que pertenecería al tratamiento del no-ser). ${ }^{53}$ Adhiriendo a

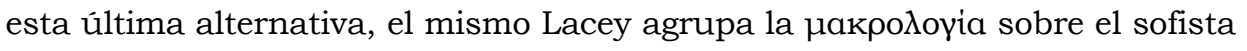
con los otros dos ejemplos (el del tejido y el del mito) y, como consecuencia de ello, sugiere que los géneros del "ser", de lo "mismo" y de lo "otro" que aparecen en Sofista podrían ocupar el lugar de los àoẃpata que se plantean en Politico, es decir el de aquellas realidades hacia las que apunta la investigación ${ }^{54}$.

Entonces, a partir de los tres niveles del diálogo Politico planteados por Lane y de la propuesta de Lacey, es posible pensar que, en el diálogo Sofista, el pescador representa el paradigma del sofista, mientras que esta última funciona, de forma implícita, como una especie de nuevo paradigma de algo mucho mayor. Recordemos que, hasta el momento, nos hemos detenido en pasajes del Fedro y del Político con el fin de iluminar las vinculaciones entre división y dialéctica

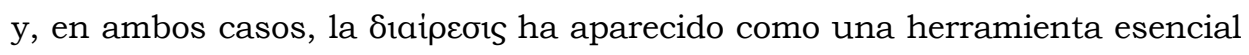
para la dialéctica. Por lo tanto, podemos concebir las divisiones efectuadas en el Sofista sobre la figura homónima como un ejercicio de carácter propedéutico que se lleva a cabo con miras a la dialéctica, dialéctica ejecutada sobre los objetos hacia los que apunta toda la investigación. En este sentido, el sofista como $\pi \alpha \varrho \alpha ́ \delta \varepsilon \uparrow \gamma \mu \alpha$ estaría cumpliendo con su dimensión metodológica (i.e. con una práctica que habitúa al inexperto en el método que se utilizará sobre un objeto mayor), pero, según entendemos, esa misma figura cumple además con la otra dimensión del $\pi \alpha \varrho \alpha ́ \delta \varepsilon \uparrow \gamma \mu \alpha$, aquella relacionada con las similitudes entre los objetos menores y mayores de un determinado diálogo.

arte de tejer -que fue bastante pesada-, esa otra sobre la retrogradación del universo y también aquélla -a propósito del sofista- sobre la existencia del no ser".

52 Cf. Campbell, L., The Sophistes and Politicus of Plato, A revised text and English notes, Oxford: Clarendon Press, 1867, p. 112, quien al comentar el pasaje en cuestión, sostiene que el motivo de la digresión era el de calmar la inquietud que genera la longitud de las exposiciones sobre el tejido, así como el mito y el debate sobre la naturaleza del sofista.

${ }^{53}$ Cf. Lacey, A.R., "Plato's Sophist and the Forms", en: The Classical Quarterly. New Series, v. IX,

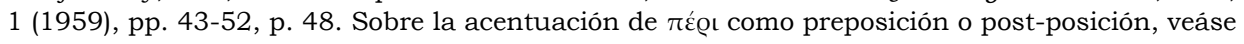
especialmente Luraghi, S., On the Meaning of Prepositions and Cases. The expression of semantic roles in Ancient Greek, Ámsterdam: John Benjamins Publishing Co., 2003, p. 81. Además, consúltese la traducción francesa de Brisson, L. y Pradeau, J.-F., Platon. Le Politique, París: Éditions Flammarion, 2003, p. 147, quienes parecen inclinarse por la segunda opción planteada por Lacey: "notre long exposé, sur le tissage, sur la rétrogradation de l'univers et sur le sophiste quant à l'existence du non-être".

${ }^{54}$ Lacey, A., o.c., p. 48. 


\section{La definición del sofista y el anticipo del rasgo determinante del no-ser}

El uso del tipo de $\pi \alpha \varrho \alpha ́ \delta \varepsilon \vdash \gamma \mu \alpha$ que estamos estudiando implica -además del aspecto metodológico ya tratado- una explicitación de ciertas similitudes entre el modelo en cuestión y un objeto mayor, similitudes que permiten ubicar a este último dentro de una determinada estructura. Asimismo, teniendo en cuenta que los $\pi \alpha \varrho \alpha \delta \varepsilon \dot{\gamma} \gamma \mu \alpha \tau \alpha$ se utilizan para entrenar a un inexperto, Goldschmidt advierte que ese entrenamiento permite habituar al aprendiz a los modos de una investigación objetiva. Es decir, de una investigación en la que su atención puede concentrarse sobre lo que el objeto es y no distorsionarse por aquello que él, como inexperto, pretende que el objeto sea ${ }^{55}$. En la misma línea, El Murr añade que un $\pi \alpha \varrho \alpha ́ \delta \varepsilon r \gamma \mu \alpha$ no solo debe presentar un asunto complejo de forma simple, sino que además debe incorporar de manera imparcial cuestiones que, en el objeto principal, entrañan algún tipo de conflicto ${ }^{56}$. A partir de estas consideraciones, nuestro próximo objetivo será determinar en qué medida esos rasgos que se cumplen en el uso del $\pi \alpha \varrho \alpha ́ \delta \varepsilon \uparrow \gamma \mu \alpha$ explícito del diálogo -hablamos del pescador con caña- permiten describir la función del sofista.

Ante todo cabe señalar que el sofista se encuentra a mitad de camino entre la simpleza del pescador con caña y la complejidad de los géneros mayores. Al comienzo de la discusión, el Extranjero subraya que el sofista es "dificil" ( $\chi \alpha \lambda \varepsilon \pi o ́ \varsigma, 218 \mathrm{~d} 3$ ) de capturar $y$, dado que es preferible abordar primero ejemplos

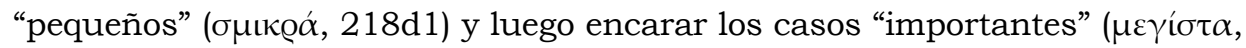
218d2), decide apelar a un $\pi \alpha \varrho \alpha ́ \delta \varepsilon \gamma \gamma \mu \alpha$. Entonces, incorpora, en primer lugar, el pescador con caña (218e) y, en segundo lugar, el sujeto que produce con una sola técnica todas las cosas (233d). Ambos paradigmas introducen aspectos esenciales del quehacer sofístico: el primero, mediante su captura de peces en las aguas, permite iluminar la caza de jóvenes que los sofistas llevan a cabo en la $\pi$ ó $\lambda ı$, mientras que el segundo permite, mediante su técnica que lo abarca todo, iluminar la tendencia omnimoda del sofista. No obstante, si el sofista es una materia dificil de abordar -para la cual se demanda el uso de paradigmas-, claramente no es la más dificultosa del diálogo. Una vez que la cuestión del no-ser irrumpe en la conversación, Teeteto sostiene que la eventual aplicación del nombre $\mu$ ஸ̀ óv a una cosa no solo resulta "dificil" ( $\chi \alpha \lambda \varepsilon \pi$ ós, 237c5), sino "casi completamente imposible de responder" (237c5). Por lo tanto, si la caza

\footnotetext{
${ }^{55}$ Goldschmidt, V., o.c., pp. 23-26.

${ }^{56}$ El Murr, D., o.c., pp. 2-4.
} 
del sofista es dificultosa, más dificultosa aun es la cuestión que gira en torno

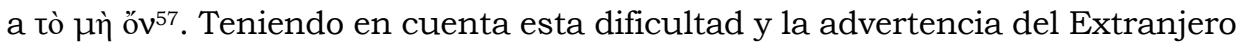
respecto del uso de ejemplos pequeños para encarar los casos importantes, el análisis del no-ser debería estar precedido por algún tipo de $\pi \alpha \rho \alpha ́ \delta \varepsilon v \gamma \mu \alpha$. De hecho, retomando el diálogo Politico, el mismo Extranjero sostiene la importancia de ese recurso, al confesar "iQué difícil es... poder presentar de modo

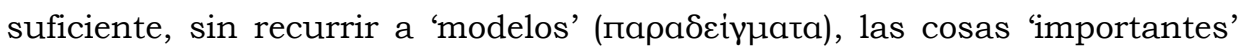
( $\mu \varepsilon \nmid \zeta \dot{v} v \omega v)$ !" (277d1-2). Esas cosas importantes no son otras que las realidades incorpóreas que el Extranjero presentará luego (285e-286a) ${ }^{58}$, y, en el caso de Sofista, la figura homónima -tal cual la construyen los interlocutores-funciona

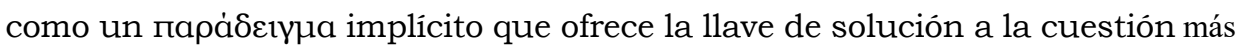
importante del diálogo: el problema del no-ser.

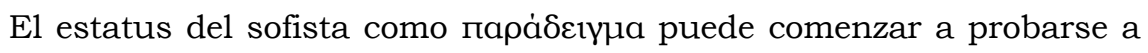
partir del entrenamiento que supone su definición. El inexperto Teeteto inicia dicho entrenamiento con un objeto neutral como el pescador y luego pasa a ocuparse del sofista que, si bien implica una serie de compromisos mayores, al mismo tiempo representa un objeto más simple y menos conflictivo que el no-ser. Teeteto puede investigar al sofista preocupado por lo que ese objeto es y no por lo que pretende que sea ${ }^{59}$, mientras que la investigación acerca del no-ser se encuentra signada por un obstáculo que condiciona la visión que se tiene de él. El padre Parménides -que emerge desde el horizonte como un emblema venerable y temible que prohíbe el tránsito por los territorios del no-ser- obliga

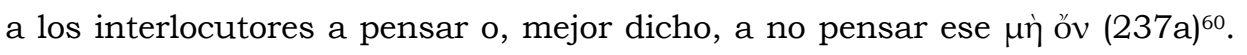
Por lo tanto, Teeteto junto al Extranjero deben hacer el sacrificio de superar aquello que Parménides pretende sobre el no-ser (que no sea) y alcanzar lo que el no-ser es ${ }^{61}$. Pero ese camino sacrificial y parricida ha sido allanado por el uso del $\pi \alpha \varrho \alpha ́ \delta \varepsilon \uparrow \gamma \mu \alpha$ implícito que representa el sofista. En efecto, es gracias a su

\footnotetext{
57 Asimismo, lineas antes, el Extranjero había afirmado que tanto parecer sin llegar a ser como

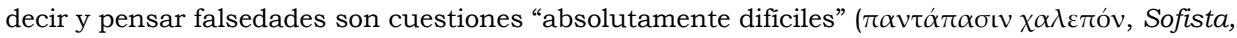
236e5-237a1).

$58 \mathrm{Al}$ respecto, cf. Miller, M., o.c., p. 58.

59 Sobre esa lógica del $\pi \alpha \varrho \alpha ́ \delta \varepsilon r \gamma \mu \alpha$ que ya hemos comentado, véase Goldschmidt, V., o.c., p. 20.

${ }^{60}$ El Extranjero cita los versos iniciales del fragmento 7 del poema parmenídeo en 237a y luego en 258e.

${ }^{61}$ Con respecto al parricidio, pueden consultarse los trabajos de Peck, A., "Plato's Parmenides. Some Suggestions for Its Interpretation. Part II”, en: Classical Quarterly, v. V, 4 (1954), pp. 31-46 y Malcom, J., "On What is Not in Any Way in the Sophist", en: Classical Quarterly, v. XXXV, 2 (1985), pp. 520-523 y, por otro lado, los de De Rijk, L.M., Plato's Sophist. A Philosophical Commentary, Ámsterdam: North-Holland, 1986 y O’Brien, D., Le non-être. Deux études sur le Sophiste de Platon, Sankt Augustin: Academia Verlag, 1995, para quienes no se comete tal parricidio.
} 
particular caracterización que, en el diálogo, surge la idea que permitirá dilucidar aquello que el no-ser es. Veamos entonces cómo se opera esa caracterización.

Desde 221c hasta 233c, el Extranjero y Teeteto intentan definir al sofista, pero este se les aparece de diversos modos: como cazador, como mercader, como discutidor e incluso como purificador del alma. La reiteración de términos como

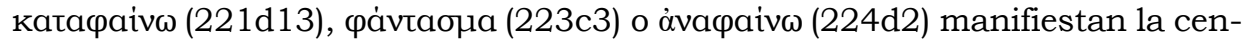
tralidad de las apariencias que si bien en principio refieren a esa circunstancia particular del aparecer del sofista, luego terminan señalando la característica esencial de su proceder. Con el objeto de otorgarle sentido a esa proliferación de apariciones, el Extranjero decide recomenzar la definición en el ámbito de la técnica productiva y, entonces, el sofista adquiere el rasgo esencial que mantendrá hasta el final de la obra: la producción de una sabiduría aparente que lo hace semejarse al sabio "sin serlo" (ov̉k őv, 233c8) ${ }^{62}$. Evidentemente, a partir de esta caracterización, el sofista se erige en lo otro, en lo diferente respecto del sabio y su identidad termina descansando en la alteridad. Cabe observar que esa alteridad es incorporada por medio del oủk őv y que, en realidad, es el resultado final del derrotero de la definición. Todo el proceso llevado a cabo por los interlocutores con el objeto de definir al sofista estaría poniendo en evidencia un particular movimiento que supone intentar acercarse a su esencia para ser expulsado hacia sus apariencias, hacia lo otro del sofista. Y es en ese punto de la discusión en el que el estatus de nuestra figura anticipa, como un ejemplo a pequeña escala, lo esencial del concepto verdaderamente dificultoso del diálogo: el no-ser.

Repasando de manera sucinta el argumento del diálogo, podemos señalar que la cuestión del no-ser surge a raíz de las dificultades que plantean el "semejar, sin llegar a ser" y el "decir algo, pero no la verdad" (236d), pues el que pretende utilizar estas expresiones para condenar al sofista cae en una contradicción: la de suponer que "lo que no es" es. Por esa razón, los interlocutores emprenden una analítica del no-ser. Sin embargo, dado que ese no-ser es una entidad que "no es de ningún modo" ( acaba con una serie de aporías que demuestran que "lo que no es" no puede

\footnotetext{
${ }^{62}$ Según entendemos, el sentido de las primeras seis definiciones del sofista no habría que buscarlo en cada una de ellas por separado, sino teniendo en cuenta el conjunto. Por el contrario, algunos intérpretes (Li Carrillo, V., o.c., pp. 176-84, Oscayan, S., "On six definitions of the Sophist: Soph. 221c-231e", en: The Philosophical Forum, 4 (1972), pp. 174-254 y Wolff, F., "Le chasseur chassé: les définitions du sophiste", en: Aubenque, P. (ed.), Études sur le Sophiste de Platon, Nápoles: Élenchos, 1991, pp. 17-52) han intentado ver los referentes de cada una de esas definiciones en sujetos o prácticas históricas particulares.
} 
aplicarse a nada de lo que es y que, al mismo tiempo, nada de lo que es puede añadirse a eso que no es de ningún modo (237b-239c) ${ }^{63}$. En consecuencia, el desafio que se le presenta a los interlocutores es el de individualizar alguna forma de no-ser que permita pensarlo y decirlo. Y esa forma será aquella que el sofista como $\pi \alpha \varrho \alpha ́ \delta \varepsilon \gamma \gamma \mu \alpha$ ha incorporado implícitamente. Hablamos de la forma de la alteridad, pero ¿de qué manera esta forma es reincorporada y vinculada al no-ser?

En la sección donde se pone a prueba la capacidad de combinación de los grandes géneros, el Extranjero pregunta a Teeteto si el género de la diferencia es una quinta forma (aparte del movimiento, del reposo, de la identidad y del ser) o si en realidad lo diferente y el ser son dos nombres aplicados a un mismo género (255c8-10). Ante todo, cabe señalar que en esta pregunta resuena aquella que Sócrates, en las primeras líneas del diálogo, le dirigió al Extranjero al intentar dilucidar si sofista, político y filósofo eran tres nombres aplicados a un mismo género o los nombres de tres géneros distintos (217a6-8). En ambos

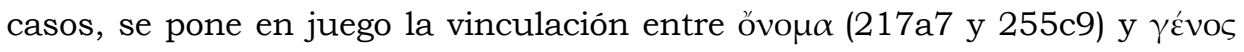
(217a7 y 255c9) y si en el primero, Sócrates comenzaba a cuestionar el estatus filosófico del Extranjero, en el segundo, el mismo Extranjero se encuentra, justamente, demostrando ese estatus. Asimismo, no debe soslayarse que, en el primer caso, se introducen el filósofo y el sofista (junto al político) y, en el segundo caso, los géneros del ser y de la diferencia. En efecto, si tenemos en cuenta los pares filósofo-ser y sofista-no-ser que se han puesto en paralelo líneas antes (254a4-254b1), podría pensarse que ambas preguntas funcionan como hitos de la trayectoria del Extranjero que, desde su lugar de filósofo, comienza definiendo al sofista y, por medio de él, dilucida el no-ser.

Volviendo a la pregunta del Extranjero, como Teeteto no parece capaz de responderla, aquel retoma una cuestión familiar sugiriéndole que él estará

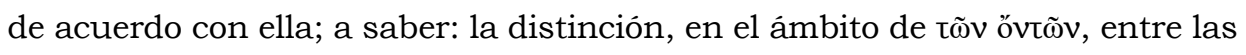
cosas que se enuncian "en sí mismas y por sí mismas" y las cosas que lo son "siempre en relación con otras cosas" ( $\pi$ @ò $\alpha \alpha \lambda \lambda \alpha \alpha \varepsilon \grave{i}, 255 c 15){ }^{64}$. En ese sentido,

${ }^{63}$ Al respecto, véase Marcos de Pinotti, G.E., Platón ante el problema del error. La formulación del
Teeteto y la solución del Sofista, Buenos Aires: Fundec, 1995, pp. 114-118.
64 Esta distinción es interpretada por algunos críticos de manera ontológica (Bluck, R., o.c.,
p. 148; Reale, G., Per una nuova interpretazione di Platone. Rilettura della metafisica dei grandi
dialoghi alla luce delle dottrine non scritte, Milán: Vita e Pensiero, 1991, pp. 252-255 y Movia,
G., Apparenza Essere E Verità. Commentario Storico-Filosofico Al Sofista Di Platone, Milán: Vita e
Pensiero, 1991, pp. 334-51) y, por otros, de forma lógico-lingüística (Moravcsik, J.M.E., "Being
and Meaning in the Sophist", en: Acta Philosophica Fennica, 14 (1962), pp. 23-78, pp. 53-54;
Seligman, P., Being and Not-Being. An Introduction to Plato's Sophist, La Haya: Martinus Nijhoff, ARETÉ Revista de Filosofia, vol. XXVIII, N² 2, 2016 / ISSN 1016-913X 
siendo lo diferente algo que es siempre en relación a otra cosa, el Extranjero sostiene que ser y diferente no son lo mismo ya que si así lo fuera, existiria algo diferente "sin ser diferente de alguna otra cosa" (255d5-6), posibilidad que es objetada de inmediato ${ }^{65}$. En conclusión, lo diferente -cuya naturaleza supone una continua expulsión hacia otra cosa, de modo que si se busca apresarlo, siempre se revelará distinto de sí-66 es comprendido como un quinto género irreductible como los otros ya distinguidos. Ahora bien, más allá de los términos de esa distinción entre ser y diferente, aquí debemos indagar una cuestión que no ha tratado la crítica: las razones por las cuales el Extranjero cree que Teeteto admitirá dicha distinción. Según pensamos, la existencia de cosas que siempre son en relación con otras debe resultarle familiar al inexperto Teeteto debido al extenso proceso de definición del sofista que supuso un movimiento de tal indole que el acercamiento a la esencia del sofista implicó una continua expulsión hacia lo otro -sus diversas apariencias-y, en última instancia, derivó en una particular caracterización del sofista como aquel que nunca es lo que es por sí mismo, sino que siempre es en relación a un otro, el sabio. En este sentido, Teeteto puede comprender con facilidad la naturaleza de los $\pi$ @ò $\alpha \alpha \lambda \lambda \alpha$ y de lo diferente porque antes se ha familiarizado con la naturaleza proteica del sofista.

Finalmente, habituados a la naturaleza de lo diferente, el Extranjero vincula esa naturaleza con el no-ser que, por ende, ya no será absoluto, sino relativo. En sus palabras, el "'no' colocado antes hace alusión a algo diferente de los nombres que siguen, o más aun de los hechos respecto de los cuales se colocan los nombres pronunciados después de la negación" (257c1-3). Por lo tanto, el ser del no-ser es revelado gracias al género de la diferencia y esta vinculación ha sido anticipada y tematizada por la definición del sofista. Si una de las funciones del $\pi \alpha \varrho \alpha ́ \delta \varepsilon \uparrow \gamma \mu \alpha$ implica establecer ciertas similitudes con el objeto principal de la investigación con el fin de ubicarlo dentro de una determinada estructura, ese propósito es consumado por el $\pi \alpha \varrho \alpha ́ \delta \varepsilon \imath \gamma \mu \alpha$ implícito que representa el sofista. Su definición ayuda a ubicar el no-ser (objeto principal de la investigación) en el género de la diferencia, pues del mismo modo en el que, en principio, hay sofista como diferencia, luego, hay no-ser como diferencia.

1974, p. 61 y Owen, G.E.L., "Plato on Not-Being”, en: Vlastos, G. (ed.), Plato: A collection of critical essays 1, Nueva York: Doubleday, 1971, pp. 223-267).

65 Sobre este argumento, véase de Vries, W., "On Sophist 255B-E", en: History of Philosophy Quarterly, v. V, 4 (1988), pp. 385-394 y Movia, G., o.c., p. 344.

${ }^{66}$ Véase Fronterotta, F., o.c., p. 132. 


\section{Conclusiones}

En el recorrido planteado en este trabajo, intentamos probar que el propósito central del diálogo Sofista es la demostración, por parte del Extranjero de Elea, de su condición filosófica. Dicha demostración comienza una vez que Sócrates duda de esa condición y alcanza su punto más álgido cuando el Extranjero, ejecutando la ciencia dialéctica, advierte que es en ese lugar donde se encuentra el verdadero filósofo. Ahora bien, antes de ejecutar la dialéctica y de enfrentarse, por medio de ella, a los géneros mayores, el mismo Extranjero decide preparar el terreno (y, sobre todo, alistar a Teeteto) a través del uso de $\pi \alpha \varrho \alpha \delta \varepsilon i ́ \gamma \mu \alpha \tau \alpha$. Y es en ese contexto en donde hemos ubicado la

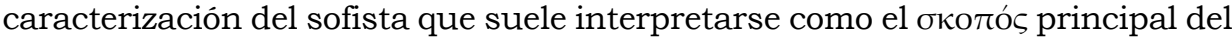
diálogo. Para nosotros, en tanto objetivo secundario y $\pi \alpha \varrho \alpha ́ \delta \varepsilon \imath \gamma \mu \alpha$ implícito, esa caracterización representa, por un lado, un ejercicio de carácter propedéutico destinado a practicar distinciones y, por otro, un ejemplo a pequeña escala del no-ser que anticipa su rasgo determinante: la alteridad. En este sentido, el foco hacia el que convergen las argumentaciones del diálogo no es propiamente la definición del sofista, sino la dilucidación del no-ser y, por extensión, el examen del ámbito eidético a manos del filósofo-dialéctico. Dado que el acceso a las realidades más altas y valiosas solo es posible tras una preparación que comienza en la esfera de las imágenes y, a partir de ella, asciende hasta la captación de lo real, el sofista estaría funcionando como una imagen puesta al servicio de esa dialéctica. Entonces, desde nuestra perspectiva, el intento de definir al sofista propicia la emergencia del perfil del filósofo no porque aquel represente lo otro respecto de este, sino porque el sofista -en tanto $\pi \alpha \varrho \alpha ́ \delta \varepsilon \imath \gamma \mu \alpha$ implícito- facilita la ejecución del método filosófico y la dilucidación de un objeto central de este método. Por todo lo dicho, podría pensarse que, a pesar de las expectativas que el propio Platón habría despertado respecto de la escritura de una obra titulada Filósofo ${ }^{67}$, la figura homónima ya se manifiesta en la performance dialéctica del Extranjero y, por lo tanto, el diálogo Filósofo ya es el diálogo Sofista.

${ }^{67}$ Cf. Sofista, 253e y Político, 257a1-c2 y 258b2-3. 


\section{Bibliografia primaria: ediciones, traducciones y comentarios}

Benardete, S., The Being of the Beautiful. Plato's Theaetetus, Sophist and Statesman, Chicago: Chicago University Press, 1984.

Bluck, R., Plato's Sophist, Manchester: Manchester University Press, 1975.

Brisson, L. y J.-F. Pradeau, Platon. Le Politique, Paris: Éditions Flammarion, 2003.

Campbell, L., The Sophistes and Politicus of Plato, Oxford: Clarendon Press, 1867.

Cordero, N., Platón, El Sofista, en: Platón, Diálogos, Madrid: Gredos, v. V, 1988.

Diès, A. (ed. y trad.), Platón, Le sophiste, en: Oeuvres complètes, t. VIII, 3ra parte, París: Les Belles Lettres, 1923.

De Rijk, L., Plato's Sophist. A Philosophical Commentary, Amsterdam: North-Holland, 1986.

Duke, E.A. y otros, Platonis Opera, recognoverunt brevique adnotatione critica instruxerunt, t. I, Oxford: OUP, 1995.

Fronterotta, F., Platone. Sofista, Milán: BUR, 2007.

Morrow, G. y J. Dillon, Proclus' Commentary on Plato's Parmenides, Princeton: PUP, 1987.

Santa Cruz, M.I. (trad.), Platón, Politico, en: Platón, Diálogos, Madrid: Gredos, v. V, 1988.

\section{Bibliografia secundaria}

Ackrill, J., "In Defence of Platonic Division", en: Wood O. y G., Pitcher (eds.), Ryle, Nueva York: Doubleday, 1970 (citamos según Ackrill, J., "In Defence of platonic division", en: Ackrill, J. (ed.), Essays on Plato and Aristotle, Oxford: OUP, 1997, pp. 93-109).

Blondell, R., The Play of Character in Plato's Dialogues, Cambridge: CUP, 2002. http:// dx.doi.org/10.1017/CBO9780511482472

Bluck, R., Plato's Sophist. A commentary, Bristol: The University Press, 1975.

Brisson, L., Lectures de Platon, París: Vrin, 2000.

Casertano, G., Il nome della cosa. Linguaggio e realtà negli ultimi dialoghi di Platone, Nápoles: Loffredo, 1996.

Cherniss, H., The Riddle of the Early Academy, Nueva York: Russell \& Russell, 1962.

Cordero, N., "El Extranjero de Elea, 'compañero' de los parmenídeos...desde 1561" en: Cornelli, G. (ed.), Plato's Styles and Characters, São Paulo: Annablume Clássica, 2012, pp. 124-138.

Cornford, F., Plato's Theory of Knowledge, Londres: Routledge \& Kegan Paul, 1935. (Traducción castellana: La teoria platónica del conocimiento, Cordero, N. y M.D. del C., Ligatto (trads.), Buenos Aires: Paidós, 2007).

De Chiara-Quenzer D., "The Purpose of the Philosophical Method in Plato's Statesman, en: Apeiron, v. XXXI, 2 (1998), pp. 91-126. http://dx.doi.org/10.1515/apeiron. 1998. 31.2.91

De Vries, W., “On Sophist 255b-e”, en: History of Philosophy Quarterly, v. V, 4 (1988), pp. 385-394.

Dixsaut, M., “Images du philosophe”, en: Kleos, v. IV (2000), pp. 191-248. 
El Murr, D., "La division et l'unité du Politique de Platon", en: Les Études philosophiques, v. III, 74 (2005), pp. 295-324. http://dx.doi.org/10.3917/leph.053.0295

El Murr, D., "Paradigm and diairesis: a response to M.L. Gill's 'Models in Plato's Sophist and Statesman", en: Plato, 6 (2006). Disponible en: http:/ /gramata.univ-paris 1. fr/Plato/article63.html, consultado el 14 de agosto de 2014.

Gill, M.L., "Models in Plato's Sophist and Stateman", en: Plato, 6 (2006). Disponible en: http://gramata.univ-paris1.fr/Plato/article27.html, consultado el 14 de agosto de 2014.

Gill, M.L., "Method and Metaphysics in Plato's Sophist and Statesman", en: Zalta, E. (ed.), The Stanford Encyclopedia of Philosophy (2009). Disponible en: http:// plato.stanford.edu/archives/win2009/entries/plato-sophstate, consultado el 14 de agosto de 2014.

Goldschmidt, V., Le paradigme dans la dialectique platonicienne, París: Presses Universitaires, 1947.

Gómez-Lobo, A., "Plato's Description of Dialectic in the Sophist 253d1-e2", en: Phronesis, v. XXII, 1 (1977), pp. 29-47. http://dx.doi.org/10.1163/156852877X00164

Gomperz, T., Griechische Denker. Eine Geschichte der antiken Philosophie, Leipzig: Veit \& Co., 1896-1909. (Traducción italiana: Pensatori Greci. Storia della filosofia antica, Bandini, L. (trad.), v. II., Firenze: La Nuova Italia Editrice, 1933-1950).

Griswold, C.L., "Logic and Metaphysics in Plato's Sophist", en: Giornale di Metafisica, v. XXXII (1977), pp. 555-570.

Griswold, C.L., Self-Knowledge in Plato's Phaedrus, New Haven: Pennsylvania State University Press, 1986.

Gulley, N., "Plato's Theory of Recollection", en: The Classical Quarterly. New Series, v. IV, $3 / 4$ (1954), pp. 194-213.

Ionescu, C., "Dialectic in Plato's Sophist: Division and the Communion of Kinds", en: Arethusa, v. XLVI, 1 (2013), pp. 41-64. http://dx.doi.org/10.1353/are.2013.0003

Kahn, C., "The Place of the Statesman in Plato's Later Work", en: Rowe, C. (ed.), Reading the Statesman, Sankt Augustin: Academia Verlag, 1995, pp. 49-60.

Kato, S., "The Role of Paradeigma in the Statesman", en: Rowe, C. (ed.), Reading the Statesman, Sankt Augustin: Academia Verlag, 1995, pp. 162-172.

Lacey, A. R., "Plato's Sophist and the Forms", en: The Classical Quarterly. New Series, v. IX, 1 (1959), pp. 43-52.

Lane M.S., Method and Politics in Plato's Statesman, Cambridge: CUP, 1998. http:// dx.doi.org/10.1017/CBO9780511518492

Li Carrillo, V., "Las definiciones del sofista”, en: Episteme, 1261 (1959-1960), pp. 83-184.

Lloyd, A.C., "Plato's Description of Division", en: Classical Quarterly. New Series, v. II (1954), pp. 105-12.

Luraghi, S., On the Meaning of Prepositions and Cases. The Expression of Semantic Roles in Ancient Greek, Ámsterdam: John Benjamins Publishing Co., 2003. http:// dx.doi.org/10.1075/slcs.67

Malcom, J., "On What is Not in Any Way in the Sophist", en: Classical Quarterly, v. XXXV, 2 (1985), pp. 520-523. http://dx.doi.org/10.1017/S0009838800040362

ARETÉ Revista de Filosofia, vol. XXVIII, Nº 2, 2016 / ISSN 1016-913X 
Marcos de Pinotti, G.E., Platón ante el problema del error. La formulación del Teeteto y la solución del Sofista, Buenos Aires: Fundec, 1995.

Mié, F., Dialéctica, predicación y metafisica en Platón. Investigaciones sobre el Sofista y los diálogos tardíos, Córdoba: Ediciones del Copista, 2004.

Miller, M.H., The Philosopher in Plato's Statesman, Las Vegas: Parmenides Publishing, 2004.

Moravcsik, J., "Being and Meaning in the Sophist", en: Acta Philosophica Fennica, v. XIV (1962), pp. 23-78.

Moravcsik, J., "The Anatomy of Plato's Divisions", en: Exegesis and Argument, Phronesis Suppl., v. I (1973), pp. 324-348.

Motta, A., "The Visible Cosmos of Dialogues: Some Historical and Philosophical Remarks about Plato in the Late Antique Schools", en: Archai, v. XII (2014), pp. 11-18. http://dx.doi.org/10.14195/1984-249X_12_1

Movia, G., Apparenza Essere E Verità. Commentario Storico-Filosofico Al Sofista Di Platone, Milano: Vita e Pensiero, 1991.

Nehamas, A., The Art of Living: Socratic Reflections from Plato to Foucault, Berkeley: University of California Press, 1998.

O’Brien, D., Le non-être. Deux études sur le Sophiste de Platon, Sankt Augustin: Academia Verlag, 1995.

Oscayan, S., "On Six Definitions of the Sophist: Soph. 221c-231e", en: The Philosophical Forum, v. IV (1972), pp. 174-254.

Owen, G., "Plato on the Undepictable", en: Nussbaum, M. (ed.), Logic, Science and Dialectic: Collected Papers in Greek Philosophy, Londres: Duckworth, 1986.

Owen, G., "Plato on Not-Being", en: Vlastos, G. (ed.), Plato: A collection of critical essays 1, Nueva York: Doubleday, 1971, pp. 223-267. http://dx.doi.org/10.1007/978-1349-86203-0_13

Palumbo, L., Il non essere e l'apparenza: sul Sofista di Platone, Nápoles: Loffredo, 1994.

Patterson, R., Image and Reality in Plato's Metaphysics, Indianapolis: Hackett Publishing Company, 1985.

Peck, A., "Plato's Parmenides. Some Suggestions for Its Interpretation. Part II", en: Classical Quarterly, v. V, 4 (1954), pp. 31-46. http://dx.doi.org/10.1017/ S0009838800007862

Philip, J., "Platonic Diairesis", en: Transactions and Proceedings of the American Philological Association, v. XCVII (1966), pp. 335-358. http://dx.doi.org/10.2307/2936018

Proclo, Commento alla Repubblica di Platone, Abbate, M. (trad.), Milán: Bompiani, 2004.

Reale, G., Per una nuova interpretazione di Platone. Rilettura della metafisica dei grandi dialoghi alla luce delle dottrine non scritte, Milán: Vita e Pensiero, 1991.

Rosen, S., Plato's Sophist. The Drama of Original and Image, New Haven: Yale University Press, 1983.

Rosen, S., Plato's Statesman: the web of Politics, New Haven: Yale University Press, 1995.

Riginos, A., Platonica: the Anecdotes concerning the Life and Writings of Plato, Leiden: Brill, 1976.

Ryle, G., Plato's progress, Cambridge: CUP, 1966. 
Santa Cruz, M.I., "Division et dialectique dans le Phèdre", en: Rossetti, L. (ed.), Understanding The Phaedrus, Sankt Augustin: Academia Verlag, 1992, pp. 253-256.

Sayre, K., Metaphysics and Method in Plato's Statesman, Nueva York: CUP, 2006. http:/ / dx.doi.org/10.1017/CBO9780511584596

Scodel, H., Diaeresis and Myth in Plato's Statesman, Gotinga: Vandenhoeck und Ruprecht, 1987. http://dx.doi.org/10.13109/9783666251832

Seligman, P., Being and Not-Being. An Introduction to Plato's Sophist, La Haya: Martinus Nijhoff, 1974.

Stenzel, J., Studien Zur Entwicklung Der Platonischen Dialektik Von Sokrates Zu Aristoteles, Leipzig: 1931. (Traducción inglesa: Allan, D., Plato's Method of Dialectic, New York: Clarendon Press, 1940).

Tarrant, H., Plato's First Interpreters, Nueva York: Cornell University Press, 2000. http:/ / dx.doi.org/10.5040/9781472597861

Trevaskis, J., "Division and Its Relation to Dialectic and Ontology in Plato", en: Phronesis, v. XII, 2 (1967), pp. 118-129. http://dx.doi.org/10.1163/156852867X00084

Vlastos, G., Socrates. Ironist and Moral Philosopher, Cambridge: CUP, 1991. http:// dx.doi.org/ 10.1017/CBO9780511518508

White, D., Myth, Metaphysics and Dialectic in Plato's Statesman, Chippenham: Ashgate Publishing Limited, 2007.

Wolff, F., "Le chasseur chassé: les définitions du sophiste", en: Aubenque, P. (ed.), Études sur le Sophiste de Platon, Nápoles: Élenchos, 1991, pp. 17-52.

Recibido: $13 / 04 / 15$

Aceptado: 06/11/15 